\title{
Changes in motor unit numbers in patients with ALS: a longitudinal study using the adapted multiple point stimulation method*
}

\author{
FC Wang ${ }^{1}$, O Bouquiaux ${ }^{1}$, V De Pasqua ${ }^{1}$ and PJ Delwaide ${ }^{2}$
}

\begin{abstract}
University Department of Physical Medicine and Rehabilitation, Hôpital du Sart Tilman, and ${ }^{2}$ From the University Department of Neurology, Hôpital de la Citadelle, B-4000 Liège, Belgium
\end{abstract}

\section{Correspondence: \\ DrFC Wans \\ Department of Physical Medicine and \\ Rehabilitation \\ CHU Sart Tilman B35 \\ B-4000 Liège, Belgium \\ Tel: 32/4/366.76.44 \\ Fax: 32/4/366.72.30 \\ E-mail: fc.wang@chu.uls.ac.be}

Received 12 November 2001

Revised 31 January 2002

Accepted 11 February 2002
METHOD: The adapted multiple point stimulation (AMPS) method for calculating motor unit numbers (MUNE) was applied in 12 patients with amyotrophic lateral sclerosis (ALS) before riluzole therapy $\left(T_{0}\right)$ and again after 4, 8 and 12 months of treatment.

RESULTS: Paired Student's t-test indicated a significant decrease of thenar MUNE and compound muscle action potential (CMAP) size at each 4-monthly interval, while average surface motor unit potential (SMUP) size did not change significantly over time. The rate of motor unit (MU) loss at month 4 was more than $20 \%$ in six patients (group 1) and less than $20 \%$ in six other patients (group 2). Comparison of groups 1 and 2 by Mann-
Whitney U-testing indicated that percent changes in thenar MUNE and CMAP size compared to baseline were significantly different at months 4, 8 and 12, while no difference between the two groups was found for average SMUP size variations. In the group with a slow rate of MU loss, CMAP size remained stable, while in the group with a rapid rate of MU loss, there was a dramatic reduction in size of the CMAP. A positive correlation was found between percent change in thenar MUNE at $\mathrm{T}_{4}$ and at $\mathrm{T}_{12}(\mathrm{P}<0.001)$.

CONCLUSION: AMPS is a useful technique to document MUNE, SMUP size and CMAP size changes over time in patients with ALS. (ALS 2002; 3: 31-38)

\section{Introduction}

Motor unit number estimate (MUNE) quantization seems to be the most reliable procedure for measuring the loss of motor neurons in clinical trials. ${ }^{1-4}$ In the perspective of new clinical trials of promising drugs intended for patients with amyotrophic lateral sclerosis (ALS), longitudinal studies are essential. MUNE techniques might therefore provide a useful approach.

Since $1971,{ }^{5}$ various procedures have been proposed for calculating MUNE. All these techniques rely on the same basic principle. The MUNE is determined through division of the supramaximal compound muscle action potential (CMAP) size by the average surface motor unit potential (SMUP) size. Average SMUP size estimates can be made by measuring all-or-nothing responses at threshold stimulation, ${ }^{5-7}$ by recording single motor unit (MU) F-waves, ${ }^{8}$

*Presented in part at the First International Symposium and Workshop on Motor Unit Number Estimation; Snowbird, Utah, 13-15 July, 2001. from spike-triggered averaging ${ }^{9}$ or from measurements of CMAP variance. ${ }^{10}$ In the present study, the adapted multiple point stimulation (AMPS) method was chosen.,11 AMPS is a simple, non-invasive, painless, rapidly executed procedure, which does not require any specific recording system or software. This method is thus easily applicable in routine clinical use. In addition, AMPS seems to be devoid of methodological bias.

The current study was designed, over a period of one year, to analyse thenar MUNE and the size of the remaining $\mathrm{MU}$ and CMAP variations by using the AMPS method in patients with ALS.

\section{Patients and methods}

\section{Participants}

Data were collected from 20 consecutive patients with ALS after having obtained their informed consent. These patients underwent motor and sensory nerve conduction 
measurements in upper and lower limbs bilaterally, and concentric needle recordings from at least three limbs, including the thenar muscles where MUNE were obtained. All patients fulfilled the clinical and electrophysiological criteria for definite ALS. ${ }^{12}$ Moreover, patients were screened to exclude any additional pathology affecting peripheral nerves, muscles or neuromuscular junctions. We excluded carpal tunnel entrapment neuropathy on the basis of clinical examination and electrophysiological tests (motor conduction velocity with terminal latency index and palmar stimulation of sensory fibres). None received drug therapy initially, in particular riluzole; but all patients received riluzole after the first electrophysiological and clinical evaluation $\left(\mathrm{T}_{0}\right)$.

AMPS was performed on the right side or, if amyotrophy was present at baseline, on the side with the lesser thenar atrophy. AMPS was applied at baseline $\mathrm{T}_{0}$ and after 4,8 and 12 months of a riluzole therapy $\left(\mathrm{T}_{4}, \mathrm{~T}_{8}, \mathrm{~T}_{12}\right)$. MUNE, average SMUP size and CMAP size were measured in all patients at $\mathrm{T}_{0}$ and each 4-month interval. With a view to normalizing the results, percent changes compared to baseline were calculated for the three variables using the following formula:

\section{$\left[\left(\mathrm{T}_{0}\right.\right.$ value-control visit value $) / \mathrm{T}_{0}$ value $] \times 100$.}

Results in patients were also compared with those from 70 healthy control subjects of both sexes and ages ranging from 19 to 93 years. As the three variables studied depend on age, each patient's result was assessed by comparing it with the normal limits in terms of age.,13

Thirteen patients with ALS completed this study over the one-year period. Four patients died (two died 9 and 11 months after the onset of symptoms); three patients were lost to follow-up for unknown reasons; one additional patient was eliminated because of missing data. The results for the remaining 12 patients are analyzed in the present paper.

\section{AMPS technique}

\section{Electrode placement}

AMPS was originally designed for median-innervated thenar muscles. The stigmatic and reference recording electrodes consisted of silver foil $4 \mathrm{~cm}$ long by $0.8 \mathrm{~cm}$ wide. The stigmatic electrode was positioned transversely over the thenar eminence, as close as possible to the muscle endplates. The reference electrode was attached over the proximal phalanx of the thumb. The ground electrode (silver foil) was fixed over the dorsum of the wrist. In this longitudinal study, a meticulous replication of electrode placement was sought by measuring in each patient the precise distance between the stimulating electrode and the tip of the thumb. The stimulating electrodes (Medelec Model LBS 53051; interelectrode distance: $2.5 \mathrm{~cm}$ ) were moved over the median nerve from the wrist to the elbow with the cathode distal. machine (Nicolet Instrument Corp.). SMUP and compound motor responses were recorded with a gain of $50-100 \mu \mathrm{V} /$ division and were evoked by constant-current square stimuli of 0.05 ms duration, at a rate of $1 \mathrm{~Hz}$, with a weak intensity gradually increased from a subthreshold value by incremental steps of 0.1-0.5 mA. CMAP were evoked by stimuli of $0.2 \mathrm{~ms}$ duration at a rate of $1 \mathrm{~Hz}$, stimulating electrodes placed $7 \mathrm{~cm}$ proximal to the stigmatic electrode (supramaximal intensity was defined as $150 \%$ of the stimulus intensity giving a maximal response). Surface recordings were filtered with a $20 \mathrm{~Hz}-5 \mathrm{kHz}$ bandpass. The hand temperature was maintained above $30^{\circ} \mathrm{C}$.

\section{Description of the AMPS method}

AMPS was a two-step procedure. The first step consisted of estimating the MU size by collecting and averaging 10 well-identified SMUP after stimulation at distinct points along the course of the median nerve between the wrist and the elbow. At each stimulation site, only two or three SMUP were successively evoked by incremental stimulation. The second step consisted of eliciting CMAP by supramaximal stimulation of the median nerve at the wrist $7 \mathrm{~cm}$ from the stigmatic electrode. By dividing the CMAP size by the average SMUP size, a MUNE was obtained.

Each SMUP was randomly incorporated in the estimation. However, to avoid alternation and ensure that any increment of the motor response corresponded to the activation of one single $\mathrm{MU}$, some specific criteria had to be met. SMUP had to be evoked :

- $\quad$ with distinct thresholds

- in an all-or-nothing fashion

- with no fractioning of the compound motor responses to successive identical stimuli

- in an orderly and reproducible manner.

Except for the first SMUP evoked at each selected stimulation point, the precise morphology of successive SMUP was not visualized, the overall potential representing, as it did, two or three units. It was theoretically possible to record the same SMUP twice from two different stimulation points in any one trial because their morphology might not be recognizable. To ensure that selected SMUP were different, the morphology of an individual SMUP could be reconstructed by subtracting from each compound motor response the preceding one obtained from the same stimulus site with a lower intensity. This reconstruction took place automatically when point-by-point differences were measured between successive digitized traces.

SMUP were eliminated from the estimation in the following circumstances: similar morphology at two distinct stimulation points, SMUP which did not fulfil selection criteria, and predominantly positive SMUP, as they were supposed to be elicited from distant muscles, such as lumbrical muscles. 


\section{Results}

The clinical data and results of longitudinal testing for the 12 patients with ALS are shown in Table 1. In addition, analyzes were also performed on two subsets of six patients: patients $1-6$ with a rate of $\mathrm{MU}$ loss at $\mathrm{T}_{4}$ of more than $20 \%$ (group 1), and patients $7-12$ with a rate of MU loss at $\mathrm{T}_{4}$ of less than 20\% (group 2) (Tables 1 and 2, Figure 1).

\section{Age, sex and disease duration}

Mean ages of the 12 patients with ALS were: $54.8 \pm 9.9$ years (range: $36-69) ; 52.8 \pm 10.4$ years in group 1 ; and $56.8 \pm 10.0$ in group 2 . There was no significant difference between the mean ages of groups 1 and 2 . There were four men and two women in each group. The overall mean disease duration (from the onset of symptoms) at baseline $\mathrm{T}_{0}$ was $21.2 \pm 9.0$ months. In group 1 , the mean disease duration was $20.5 \pm 9.7$ months and in group 2, $21.8 \pm 9.2$ months. There was no significant difference between the two groups.

\section{Thenar muscle involvement}

At baseline, clinical thenar amyotrophy was present in five of 12 patients with ALS: two in group 1 (33\%) and three in group 2 (50\%). After one year of riluzole therapy, thenar amyotrophy was observed in 10 of 12 ALS patients: six in group $1(100 \%)$ and four in group $2(66 \%)$.

Needle electromyography (EMG) of the thenar muscles using a standard concentric needle indicated chronic motor denervation (fibrillation potentials in fewer than four of 10 needle muscular insertions, and increased size of MU potential) in eight patients with ALS: three in group 1 (50\%) and five in group 2 (84\%). Subacute motor denervation (fibrillation potentials in more than four of 10 needle muscular insertions and increased size of MU potential) was observed in three patients from group 1 (50\%) and none from group $2(0 \%)$. In patient 7 (group 2), there was no EMG evidence of thenar muscle involvement.

\section{Thenar MUNE}

At baseline $\mathrm{T}_{0}$, thenar MUNE was decreased in all patients with ALS (Table 1). Mean thenar MUNE in the 12 patients were $38.5 \pm 25.5$ at $\mathrm{T}_{0}, 29.8 \pm 23.8$ at $\mathrm{T}_{4}, 23.8 \pm 21.1$ at $\mathrm{T}_{8}$ and $15.3 \pm 18.4$ at $\mathrm{T}_{12}$ (Table 1). Paired Student's $t$-test indicated a significant decrease of thenar MUNE at each 4monthly interval (Table 2). Among the four patients who died before month 12 (patients withdrawn from the longitudinal analysis), two presented a very high rate of MU loss ( $>50 \%$ at $\mathrm{T}_{4}$ ). At $\mathrm{T}_{12}$, the percent change compared to baseline reached on average $60.8 \%$ (Table 1 ). Comparison of group 1 (rate of MU loss more than $20 \%$ at $\mathrm{T}_{4}$ ) and group 2 (rate of MU loss less than $20 \%$ at $\mathrm{T}_{4}$ ) by MannWhitney U-testing indicated that percent changes compared to baseline were significantly different at $\mathrm{T}_{4}, \mathrm{~T}_{8}$ and $\mathrm{T}_{12}$ (Table 2).

\section{Average SMUP size}

Average SMUP size remained within normal limits in patient 7 at $\mathrm{T}_{0}$, patients 6 and 8 at $\mathrm{T}_{8}$, and patient 8 at $\mathrm{T}_{12}$; while all other average SMUP size values were above the upper limit of normal (Table 1). Mean average SMUP sizes in the 12 patients with ALS were $357 \pm 162 \mu \mathrm{V} . \mathrm{ms}$ at $\mathrm{T}_{0}$, $391 \pm 204 \mu \mathrm{V} . \mathrm{ms}$ at $\mathrm{T}_{4}, 334 \pm 202 \mu \mathrm{V}$.ms at $\mathrm{T}_{8}$ and $336 \pm 217 \mu \mathrm{V} . \mathrm{ms}$ at $\mathrm{T}_{12}$ (Table 1). Comparison of different means obtained at $\mathrm{T}_{0}, \mathrm{~T}_{4}, \mathrm{~T}_{8}$ and $\mathrm{T}_{12}$ by using paired Student's $t$-test did not indicate any significant difference (Table 2).

Comparison by Mann-Whitney U-testing of percent changes at $\mathrm{T}_{4}, \mathrm{~T}_{8}$ and $\mathrm{T}_{12}$ (compared to baseline) did not show any significant difference between group 1 and group 2 (Table 2 ).

\section{CMAP size}

Thenar CMAP size remained within normal limits in seven patients with ALS at $\mathrm{T}_{0}$ (four from group 1 and three from group 2), five patients at $\mathrm{T}_{4}$ (two from group 1 and three from group 2), three patients (from group 2) at $\mathrm{T}_{8}$ and two patients (from group 2) at $\mathrm{T}_{12}$; and was decreased in other patients (Table 1). Mean thenar CMAP sizes in the 12 patients were $11.6 \pm 7.1 \mathrm{mV} . \mathrm{ms}$ at $\mathrm{T}_{0}, 9.4 \pm 6.5 \mathrm{mV} . \mathrm{ms}$ at $\mathrm{T}_{4}, 6.7 \pm 5.8 \mathrm{mV} . \mathrm{ms}$ at $\mathrm{T}_{8}$ and $4.4 \pm 5.0$ at $\mathrm{T}_{12}$ (Table 1 ). Paired Student's $t$-test indicated a significant decrease of thenar CMAP size at each 4-monthly interval (Table 2).

Comparison of group 1 and group 2 by Mann-Whitney U-testing indicated that percent changes compared to baseline were significantly different at $\mathrm{T}_{4}, \mathrm{~T}_{8}$ and $\mathrm{T}_{12}$ (Table 2).

In group 1, the percent decline in CMAP size reached on average $95.5 \%$ over a one-year period. In group 2 , CMAP size remained quite stable till month 8 , and at month 12, the percent change in CMAP size was on average $47.3 \%$ (Table 1 ).

\section{Relationship between variables}

Correlation coefficients between percent changes, compared to baseline $\mathrm{T}_{0}$, in the three variables derived by using AMPS are shown in Table 3. Changes in thenar MUNE were correlated with changes in CMAP size but were not correlated with changes in average SMUP size. The latter was correlated with changes in CMAP size only when variations at month 4 in both variables were compared.

Percent changes in thenar MUNE or CMAP size calculated during distinct AMPS evaluations over time were correlated; while no correlation was found concerning changes in average SMUP size.

Figure 1 shows the positive correlation between the rate of $\mathrm{MU}$ loss at $\mathrm{T}_{4}$ and the rate of $\mathrm{MU}$ loss at $\mathrm{T}_{12}$. The six patients with a rate of $\mathrm{MU}$ loss greater than $20 \%$ at $\mathrm{T}_{4}$ (group 1) had a rate of MU loss of more than $50 \%$ at $\mathrm{T}_{12}$. Five of the six patients with a rate of MU loss less than $20 \%$ at $\mathrm{T}_{4}$ (group 2) had a rate of MU loss less than $50 \%$ at $\mathrm{T}_{12}$. 


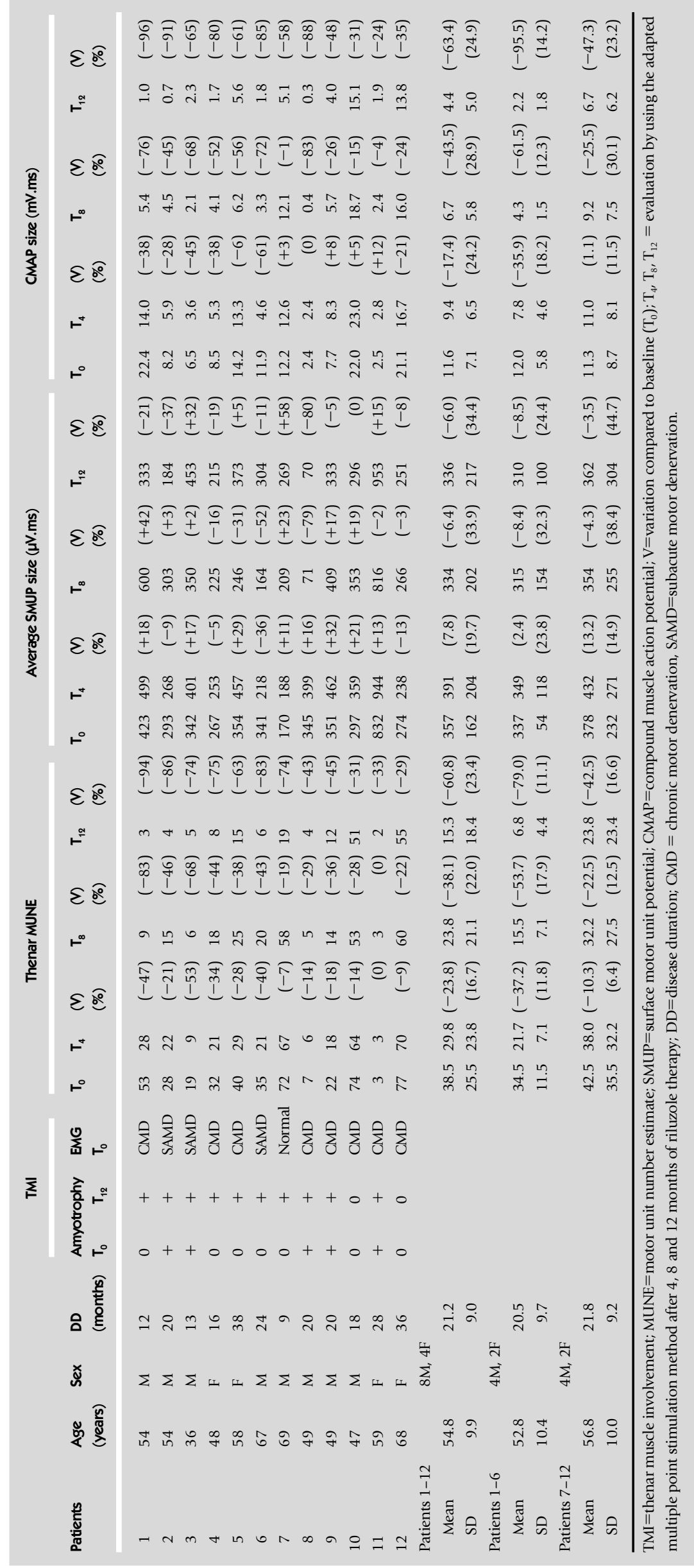


Original Research

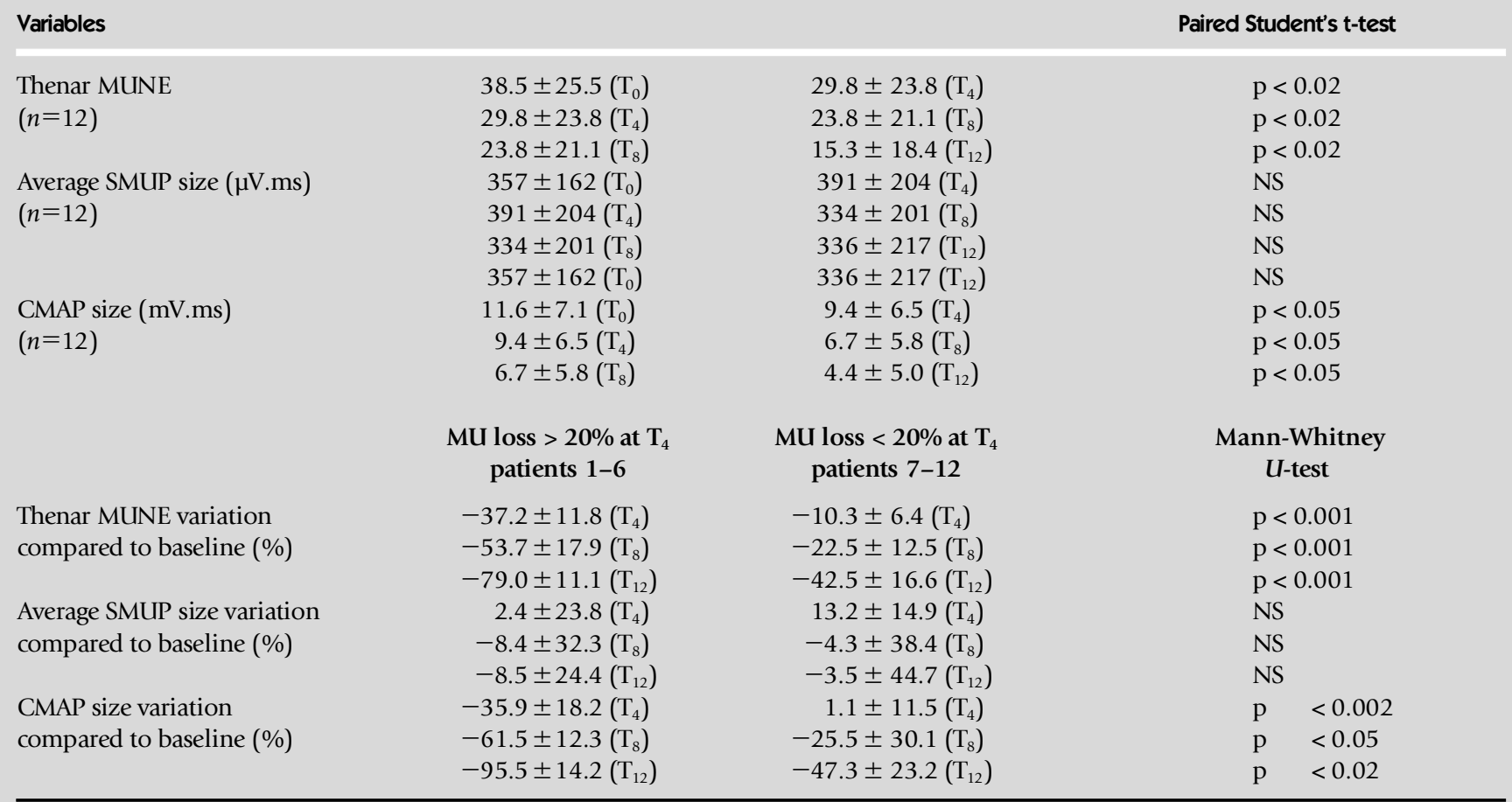

MUNE=motor unit number estimate; $\mathrm{SMUP}=$ surface motor unit potential; $\mathrm{CMAP}=$ compound muscle action potential; $\mathrm{MU}=$ motor unit;

$\mathrm{T}_{4}, \mathrm{~T}_{8}, \mathrm{~T}_{12}=$ evaluation by using the adapted multiple point stimulation method after 4,8 and 12 months of riluzole therapy.

Table 2

Statistical comparison of results between 12 patients with amyotrophic lateral sclerosis

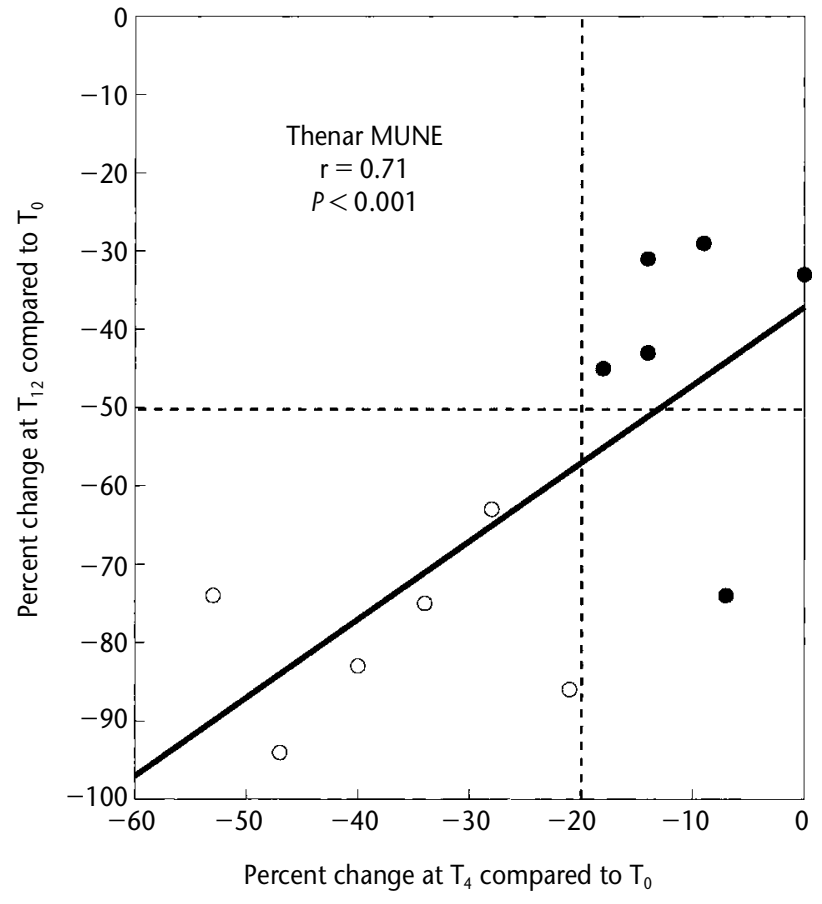

Figure 1

Relationship between the rate of motor unit loss at month 4 and the rate of motor unit loss at month 12 in 12 patients with amyotrophic lateral sclerosis. Percent change (compared to baseline) in thenar motor unit number estimate (MUNE) at $\mathrm{T}_{4}$ was more than $20 \%$ in 6 patients (circles, group 1) and was less than $20 \%$ in 6 other patients (dots, group 2).

\section{Discussion}

First of all, the reliability and practicality of AMPS will be discussed.

\section{Assumptions related to the MU recruitment by incremental stimulation}

SMUP selection criteria were established to avoid alternation. We could therefore postulate that any increment of the motor response was due to activation of an additional MU.

The sample of selected MU had to be representative of the whole population. Theoretically, techniques using incremental stimulation or near threshold SMUP activation might all be biased toward large $\mathrm{MU} \cdot{ }^{14}$ However, the arguments developed by McComas and colleagues, ${ }^{5}$ Galea and colleagues ${ }^{15}$ and Doherty and Brown ${ }^{6}$ are evidence against this possible bias. Moreover, considering the size distribution of SMUP evoked by techniques using incremental stimulation, a wide distribution with more small units than large ones was observed. This distribution was also nearly identical to those obtained by techniques in which MU were not recruited at threshold intensity as in the F-response method, ${ }^{8}$ or procedures using a MU recruitment based on voluntary contraction ${ }^{9}$ or techniques estimating the MU size by measuring the MU twitch. ${ }^{16}$ 


\section{Validity}

AMPS results were reproducible in control subjects as well as in patients with motor denervation. In 10 normal subjects, when thenar MUNE and average SMUP size estimation by the AMPS method were repeated by the same examiner on two successive days, the coefficients of variation between results from the two trials were $10.4 \%$ and $9.5 \%$ respectively. ${ }^{7}$ In patients with ALS, when AMPS was performed twice in the same session with new electrode placements for the second trial, the coefficient of variation for both MUNE and average SMUP size was 4\% between the two trials. ${ }^{11}$

\section{Ease of application}

AMPS was a fast procedure, which could be completed in about 15 minutes. Moreover, AMPS did not require any specific recording system or software. Thus, AMPS was easily applicable for clinical purposes. With the AMPS technique, it was possible to obtain a MUNE in all 70 volunteers studied, ${ }^{13}$ without technical failures. Moreover, in our experience with patients presenting with severe axonal loss, particularly in the 12 patients with ALS in the current study, MUNE were easier to obtain than in healthy volunteers. Indeed, as previously reported, ${ }^{17}$ there was less overlap of MU thresholds when denervation was severe, and alternation was therefore less noticeable. On the other hand, in partially denervated muscles the accuracy is also higher, since the sample of units is a greater fraction of the whole population. When the MU number was very low, it was sometimes possible to evoke more than three SMUP without alternation from the same point using incremental stimulation. Therefore, two or three different stimulation points along the course of the median nerve were enough to derive a MUNE. If there were less than $10 \mathrm{MU}$ remaining in some patients, the best way to derive a MUNE was sometimes to find one stimulation point from which it was possible to activate the few remaining MU without alternation. In these particular cases, AMPS was very similar to the initial estimation technique described by McComas and colleagues. ${ }^{5}$

Finally, AMPS was non-invasive and painless, as only surface electrodes and low stimulation intensities were used.

\section{Thenar MUNE}

At baseline $\mathrm{T}_{0}$, after a mean disease duration of $21.2 \pm 9.0$ months, all 12 patients with ALS had decreased thenar MUNE compared with the normal limits in terms of age previously defined ${ }^{7,13}$ in a group of 70 healthy control subjects. In patient 7 , there was neither thenar amyotrophy nor electromyographic evidence of motor denervation in thenar muscles (Table 1). Thus, in patients with ALS, decreased MUNE was probably one of the most sensitive signs of motor denervation. Paired Student's $t$-test pointed out a significant decrease of thenar MUNE every 4 months (Table 2). After one year, the MUNE decline reached on average $60.8 \%$ compared to baseline (Table 1). A more severe evolution has been found by several authors, who established that on average the MU population halved in each 6 -month period, with a drop of around $75 \%$ in the first year after diagnosis. ${ }^{11,18,19}$ This might be due to the fact that only patients who survived one year after baseline were included in the study. Two patients, with an acute form of ALS, presented very high rate of MU loss (>50\% at $\mathrm{T}_{4}$ ), and died before $\mathrm{T}_{12}$, and were therefore withdrawn from analysis.

Two subsets of six patients were defined on the basis of the rate of $\mathrm{MU}$ loss at $\mathrm{T}_{4}$, more (group 1) or less (group 2) than $20 \%$ compared to baseline. From a statistical point of view, these two groups did not differ in terms of age, disease duration from the onset of symptoms and sex. Comparison by Mann-Whitney U-testing of percent changes in thenar MUNE compared to baseline indicated a significant difference between both groups at each 4monthly interval (Table 2 ). In group 1, with a rapid rate of progression, there was thenar wasting in two patients at $\mathrm{T}_{0}$, but in all six at $T_{12}$, and EMG recordings at baseline in the six patients revealed thenar motor denervation which was chronic $(n=3)$ or subacute $(n=3)$. In group 2 , with a slower rate of progression, there was thenar wasting in three patients at $\mathrm{T}_{0}$ and in four at $\mathrm{T}_{12}$. Thenar muscle EMG data at baseline remained normal in one patient and indicated chronic motor denervation in five (Table 1).

\section{Average SMUP size}

Associated with the reductions in thenar MUNE was the enlargement of surviving units, as indicated by the increase in average SMUP sizes measured in all 12 patients, with the exception of patient 7 at $\mathrm{T}_{0}$, patient 6 at $\mathrm{T}_{8}$ and patient 8 at $\mathrm{T}_{8}$ and $\mathrm{T}_{12}$ (Table 1 ). The smallest SMUP recorded in the 12 patients with ALS was $35 \mu \mathrm{V}$.ms and the largest was $2738 \mu \mathrm{V}$.ms. No difference was observed between average SMUP size results estimated in all 12 patients with ALS by repeated AMPS testing at 4-monthly intervals. In addition, there was no statistical difference between percent changes compared to baseline calculated from both subsets of six patients (Table 2). These data were probably indicative of the fact that the patients were not at the same stage of evolution and that several parameters influenced the MU size in different ways. Among these parameters, the following ones had to be considered: 1. collateral reinnervation, which was probably more effective in the early stages, and small MU loss increased the average SMUP size; 2. the disappearance of some large units and the MU 'disintegration' phenomenon, which might occur in terminal stages, ${ }^{11,20}$ decreased the mean MU size.

\section{CMAP Size}

Values of CMAP size confirmed that collateral reinnervation is able, from an electrophysiological point of view, to compensate for motor denervation. In fact, at the time of the first examination $\left(\mathrm{T}_{0}\right)$, seven of 12 patients kept their thenar CMAP size within normal limits. However, among 
the four patients from group 1 (rate of MU loss more than $20 \%$ at $\mathrm{T}_{4}$ ) in whom CMAP size remained within normal limits at $\mathrm{T}_{0}$, only two kept this variable within the normal range at $\mathrm{T}_{4}$, and none at $\mathrm{T}_{8}$ and $\mathrm{T}_{12}$. Conversely, in the three patients from group 2 (rate of $\mathrm{MU}$ loss at $\mathrm{T}_{4}$ less than $20 \%$ ), in whom CMAP size was within normal limits at $\mathrm{T}_{0}$, the variable remained quite unchanged at $\mathrm{T}_{4}$ and $\mathrm{T}_{8}$, and even up to one year after diagnosis in two patients (Table 1). Consequently, Mann-Whitney U-testing indicated that percent changes, compared to baseline, were significantly different between groups 1 and 2 at $\mathrm{T}_{4}, \mathrm{~T}_{8}$ and $\mathrm{T}_{12}$ (Table 2).

\section{Relationships between variables}

CMAP size is the product of MUNE and average SMUP size. Correlations between changes in thenar MUNE and CMAP size (Table 3) were therefore expected. However, change in average SMUP size was correlated with change in CMAP size only at $\mathrm{T}_{4}$ (Table 3 ). We can thus postulate that CMAP size variations over time were more influenced by MUNE than by average SMUP size variations. On the other hand, CMAP size variations over time might be due to a change in the placement of recording electrodes, which should induce similar changes in average SMUP size. It seems that it was not the case in the present study, since both variables were poorly correlated. As indicated under 'Patients and Methods', in this longitudinal study a meticulous replication of recording electrode placement was sought by measuring in each patient the precise distance between the stigmatic electrode and the tip of the thumb.

The relationship between different values from the same variable, measured over time, might be a way to determine the prognostic value of the variable under analysis. From this point of view, the best correlation coefficient, between results at $\mathrm{T}_{4}$ and $\mathrm{T}_{12}$ (the most distant percent change evaluations), was found for change in thenar MUNE ( $\mathrm{r}=0.71)$ (Table 3). This correlation was indicative of a quite stable rate of $\mathrm{MU}$ loss over the oneyear period; hence, the percent change in MUNE at $\mathrm{T}_{4}$ might be considered a prognostic value of the rate of $\mathrm{MU}$ loss at $\mathrm{T}_{12}$. Figure 1 shows that in group 1 , the rate of $\mathrm{MU}$ loss at $\mathrm{T}_{12}$ compared to baseline was more than $50 \%$, while five of six patients from group 2 presented a rate of MU loss less than $50 \%$. These data give substance to the prognostic value of percent change in thenar MUNE at $T_{4}$ over a short follow-up period. Nevertheless in longer follow-up, Dantes and McComas ${ }^{18}$ and Daube ${ }^{21}$ found that the initial, usually rapid, loss of MU was followed by a slower loss of the remaining MU. In the present study, patients with ALS were not at the same stage of evolution. In fact, some patients were in the initial phase of the disease (i.e. patient 7 at $\mathrm{T}_{0}$ : thenar $\mathrm{MUNE}=72$, disease duration $=9$ months) and some others in a later phase (i.e. patient 11 at $\mathrm{T}_{0}$ : thenar $\mathrm{MUNE}=3$, disease duration $=28$ months).

\section{Conclusion}

With a view to clinical trials, it should be useful to be able to distinguish patients with ALS according to a rapid or a slow rate of progression. Besides fibrillation abundance, shape variability of MU potentials, decremental response to repetitive nerve stimulation ${ }^{22}$ and fibre density, ${ }^{4}$ MUNE techniques might be useful for this. Results obtained by AMPS, a simple, reliable, and painless method, suggest

\begin{tabular}{|c|c|c|c|c|c|c|c|c|c|c|}
\hline & & \multicolumn{3}{|c|}{ Thenar MUNE } & \multicolumn{3}{|c|}{ Average SMUP size } & \multicolumn{3}{|c|}{ CMAP size } \\
\hline & & $\mathrm{T}_{4}$ & $\mathrm{~T}_{8}$ & $T_{12}$ & $\mathrm{~T}_{4}$ & $\mathrm{~T}_{8}$ & $\mathrm{~T}_{12}$ & $\mathrm{~T}_{4}$ & $\mathrm{~T}_{8}$ & $\mathrm{~T}_{12}$ \\
\hline Thenar & $\mathrm{T}_{4}$ & / & $0.92^{+++}$ & $0.71^{+}$ & 0.12 & 0.01 & 0.03 & $0.82^{++}$ & $0.76^{+}$ & $0.62^{\circ}$ \\
\hline \multirow[t]{2}{*}{ MUNE } & $\mathrm{T}_{8}$ & / & / & $0.72^{+}$ & 0.03 & 0.22 & 0.15 & $0.69^{\circ \circ}$ & $0.72^{+}$ & $0.69^{\circ \circ}$ \\
\hline & $\mathrm{T}_{12}$ & I & l & l & 0.28 & 0.12 & 0.04 & $0.70^{\circ} \circ$ & 0.51 & $0.81^{++}$ \\
\hline Average & $\mathrm{T}_{4}$ & I & 1 & I & / & 0.32 & 0.16 & $0.66^{\circ} \circ$ & 0.16 & 0.29 \\
\hline \multirow[t]{2}{*}{ SMUP size } & $\mathrm{T}_{8}$ & / & 1 & 1 & 1 & / & 0.54 & 0.13 & 0.50 & 0.28 \\
\hline & $\mathrm{T}_{12}$ & I & l & I & I & I & l & 0.11 & 0.58 & 0.51 \\
\hline \multirow[t]{3}{*}{ CMAP size } & $\mathrm{T}_{4}$ & 1 & 1 & I & I & / & I & / & $0.65^{\circ}$ & $0.63^{\circ}$ \\
\hline & $\mathrm{T}_{8}$ & / & 1 & / & / & / & l & / & / & $0.81^{++}$ \\
\hline & $\mathrm{T}_{12} /$ & 1 & 1 & 1 & 1 & I & 1 & 1 & 1 & I \\
\hline
\end{tabular}

Table 3

Correlation coefficients ( $r$ ) between percent changes (compared to baseline) in AMPS variables 
that slow progression is characterized by a rate of MU loss of less than $20 \%$ every four months and stable CMAP size, and conversely for rapid progression.

\section{Acknowledgements}

The authors thank P Gérard and R Boyd for their valuable assistance.

\section{References}

1. Bromberg MB, Larson WL. Relationships between motorunit number estimates and isometric strength in distal muscles in ALS/MND. J Neurol Sci 1996; 139 (suppl): S38-S42.

2. Bromberg MB. Electrodiagnostic studies in clinical trials for motor neuron disease. J Clin Neurophysiol 1998; 15: $117-128$

3. Felice KJ. A longitudinal study comparing thenar motor unit number estimates to other quantitative tests in patients with amyotrophic lateral sclerosis. Muscle Nerve 1997; 20: 179-185.

4. Yuen EC, Olney RK. Longitudinal study of fiber density and motor unit number estimate in patients with amyotrophic lateral sclerosis. Neurology 1997; 49: 573-578.

5. McComas AJ, Fawcett PR, Campbell MJ, Sica RE. Electrophysiological estimation of the number of motor units within a human muscle. J Neurol Neurosurg Psychiatry 1971; 34: 121-131.

6. Doherty TJ, Brown WF. The estimated numbers and relative sizes of thenar motor units as selected by multiple point stimulation in young and older adults. Muscle Nerve 1993; 16: 355-366.

7. Wang FC, Delwaide PJ. Number and relative size of thenar motor units estimated by an adapted multiple point stimulation method. Muscle Nerve 1995; 18: 969-979.

8. Stashuk DW, Doherty TJ, Kassam A, Brown WF. Motor unit number estimates based on the automated analysis of Fresponses. Muscle Nerve 1994; 17: 881-890.

9. Brown WF, Strong MJ, Snow R. Methods for estimating numbers of motor units in biceps-brachialis muscles and losses of motor units with aging. Muscle Nerve 1988; 11: 423-432.

10. Daube JR. Statistical estimates of number of motor units in thenar and foot muscles in patients with amyotrophic lateral sclerosis or the residual of poliomyelitis. Muscle Nerve 1988; 11: 957.

11. Wang FC, Delwaide PJ. Number and relative size of thenar motor units in ALS patients: application of the adapted multiple point stimulation method. Electroencephalogr Clin Neurophysiol 1998; 109: 36-43.
12. Brooks BR. El Escorial World Federation of Neurology criteria for the diagnosis of amyotrophic lateral sclerosis. Subcommittee on Motor Neuron Diseases/Amyotrophic Lateral Sclerosis of the World Federation of Neurology Research Group on Neuromuscular Diseases and the El Escorial "Clinical limits of amyotrophic lateral sclerosis" workshop contributors. J Neurol Sci 1994; 124 (suppl): S96-S107.

13. Wang FC, Delwaide PJ. An adapted multiple point stimulation (AMPS) method for estimating the number and size of motor units. Electroencephalogr Clin Neurophysiol 1995, 97 (suppl):S164.

14. Erlanger J, Gasser HS. Electrical signs of nervous activity (Thesis). Philadelphia: University of Pennsylvania Press 1937.

15. Galea V, de Bruin H, Cavasin R, McComas AJ. The numbers and relative sizes of motor units estimated by computer. Muscle Nerve 1991; 14: 1123-1130.

16. Dengler R, Kossev A, Wohlfahrt K, Schubert M, Elek J, Wolf W. F waves and motor unit size. Muscle Nerve 1992; 15: 1138-1142.

17. Brown WF, Milner-Brown HS. Some electrical properties of motor units and their effects on the methods of estimating motor unit numbers. J Neurol Neurosurg Psychiatry 1976; 39: $249-257$

18. Dantes $M$, McComas A. The extent and time course of motoneuron involvement in amyotrophic lateral sclerosis. Muscle Nerve 1991; 14: 416-421.

19. Arasaki K, Tamaki M. A loss of functional spinal alpha motor neurons in amyotrophic lateral sclerosis. Neurology 1998; 51: 603-605.

20. Emeryk-Szajewska B, Kopec J, Karwanska A. The reorganization of motor units in motor neuron disease. Muscle Nerve 1997; 20: 306-315.

21. Daube JR. Electrodiagnostic studies in amyotrophic lateral sclerosis and other motor neuron disorders. Muscle Nerve 2000; 23: 1488-1502.

22. Wang FC, De Pasqua V, Gerard P, Delwaide PJ. Prognostic value of decremental responses to repetitive nerve stimulation in ALS patients. Neurology 2001; 57: 897-899. 